\title{
Analysis of optimized multilevel matrix converter for DFIG based wind energy conversion system
}

\author{
Shubha Baravani ${ }^{1}$, Rudranna Nanadihalli², Mohsin A. Mulla ${ }^{3}$ \\ ${ }^{1}$ Assistant Professor, Department of Electrical and Electronics Engineering, Jain College of Engineering, Belagavi, India. \\ ${ }^{2}$ Professor, Department of Electrical and Electronics Engineering, R.V. College of Engineering, Bangalore, India. \\ ${ }^{3}$ Assistant Professor, Department of Electrical Engineering, Sharad Institute of Technology College of Engineering, \\ Kolhapur District, Maharashtra, India.
}

\begin{tabular}{l}
\hline \hline Article Info \\
\hline Article history: \\
Received Feb 7, 2021 \\
Revised May 18, 2021 \\
Accepted June 3, 2021 \\
\hline Keyword: \\
optimized multilevel matrix \\
converter \\
wind power generation \\
multi-objective optimization \\
membership function \\
reliability and cost analysis
\end{tabular}

\section{INTRODUCTION}

Among the widely used induction generator types, the doubly-fed induction generator (DFIG) has been proven to be the best for the variable speed wind energy conversion system. The prospects of low maintenance and cost efficiency make DFIG superior to others [1]. The direct power conversion method, without passive components in the DC-link, has been studied by Wheeler et al. by incorporating all power electronic systems for getting sinusoidal output current [2]. Another topology of matrix converter called indirect matrix converter contains current-source rectifier and voltage-source inverter. The performance characteristics of this topology are similar to that of the direct matrix converter [3,4]. But the DC-link provides options like multi-switching frequencies in the input and output thereby reducing losses, changing the magnitude of the DC-link voltage, achieving a multi-drive operation, and enhancement of the output voltage level [5].

The half and full-bridge submodules (FBS) present in the hybrid type modular multilevel converters can manage the DC fault problem [6]. So the rate of failure and the cost of hybrid type modular multilevel converters (MMC) are higher under normal conditions as compared with half-bridge MMC [7]. On the other hand, the performance of alternate arm converter is better in terms of DC fault ride-through capability, as 
compared with half-bridge MMC. The advantages are multiple: smaller capacitor sizing, less power loss, and fewer FBS [8,9]. Conversely, the alternate arm converter has few disadvantages such as the over-utilization of power devices vis-à-vis the hybrid MMC and also that it requires DC filter with complex control method [10]. As a result, hybrid MMC is widely used as a converter topology in a wind energy conversion system. Due to the DC-fault ride-through capability and low harmonic rate, hybrid MMC, as compared to conventional threelevel converters, has various benefits. However, the rate of failure and the cost are higher. The power converters situated in remote areas require high-reliability systems [11]. Medium voltage applications are used in active redundancy configurations because pre-charging is not required during faulty conditions and fewer harmonics. Two different redundancy configurations namely: 1) voltage-sharing and 2) fixed level are used. The voltage sharing offers high reliability, less voltage stress, and high efficiency [12]. With increased reliability, saturation effect is guaranteed which then increases the total cost. The reliability and cost of the various submodules should be computed and the optimal topology of the hybrid MMC for wind energy conversion has to be derived using a multi-objective model $[13,14]$.

Numerous articles have paid researched into wind energy generation based on DFIG. A part of them have delved into the performance and control study of generation system [15] while the rest have focused on energy storage systems [16]. However, few research articles have studied the plausibility of matrix converters in wind energy conversion [17]. The matrix converter with direct topology is extensively used due to its well-defined structure. Nevertheless, the multi-level matrix converter (MLMC) using indirect topology is also introduced in the wind energy generation system [18,19]. This approach is utilized at two-level construction one at the inverter stage and the full structure at the rectification stage.

The redundancy configuration of MMC is optimized using various techniques. Xu et al. proposed a single objective function-based optimization method for setting a weighting factor for the redundancy configuration. The analysis of the redundant submodules under reliability conditions was carried out for the HVDC application [20]. To study the redundancy of hybrid MMC, an optimal design was proposed. Similarly, to analyze the interaction of the cost and reliability model of the same, Lagrange multiplier was used in the study [21]. However, a lack of proper cost-feasibility model can increase the total build expense. For the same, the optimal design is attained by incorporating the constraints of reliability and cost function. As a result, the performance of the system is boosted [22]. Kim and Lee proposed the relationship between the redundant module and the availability of half-bridge MMC. The experiment was conducted for the IGBT modules by considering different voltage ratings [23]. Diaz et al. suggested a vector control of a Modular MMC for a full operating frequency range. This method focused on the half-bridge MMC with a fixed number of submodules. Numerical analysis has been done for the hybrid MMC with active redundancy [24]. A comparison between half and full-bridge submodules has been drawn by Xie et al [25].

The reliability and cost analysis of the converters using multi-objective optimization takes the redundant submodules into consideration along with the determination of number of parallel modules is determined for the power system $[26,27]$. The multi-objective function used in the above literature does not provide rigorous results, particularly the maintenance cost, which cannot then be accessed in MMC used in wind turbines as they are not implicated on wind turbine applications. Therefore, earlier optimization techniques are not suitable to MLMC applications. The redundant submodules are thus seldom cogitated on cost and reliability analysis.

To surmount the cited problems, a multi-objective optimization-based multilevel matrix converter (MOMMC) is proposed for the wind energy conversion system. This paper introduces a model for reliability and cost for different numbers of redundant submodules. The model can handle DC fault conditions. Using this model the investigation is conducted for reliability and cost consideration. A multi-objective function is defined which generates the optimal topology for MLMC. Hence, the proposed multi-objective technique, notably, is an appropriate choice for MMCs with other submodule configurations. It is also suitable for alternate arm converter topology because the component counts and adjusts the loss in power. The studied system including the doubly-fed induction generator (DFIG) is shown in Fig. 1. In this research, two different case studies: fixed speed and variable speed have been considered. Furthermore, the active and reactive power of DFIG, rotor current, and voltage using a three-level matrix converter is presented. The paper is organized into three further headings: Section 2 describes the basic operation of a multilevel matrix converter for a wind energy generation system. The active redundancy configuration in the hybrid MMC along with reliability and cost model is explicated in Section 3. Likewise, in Section 4, two different case studies for analyzing the reliability and cost with various sub-modules are described. 

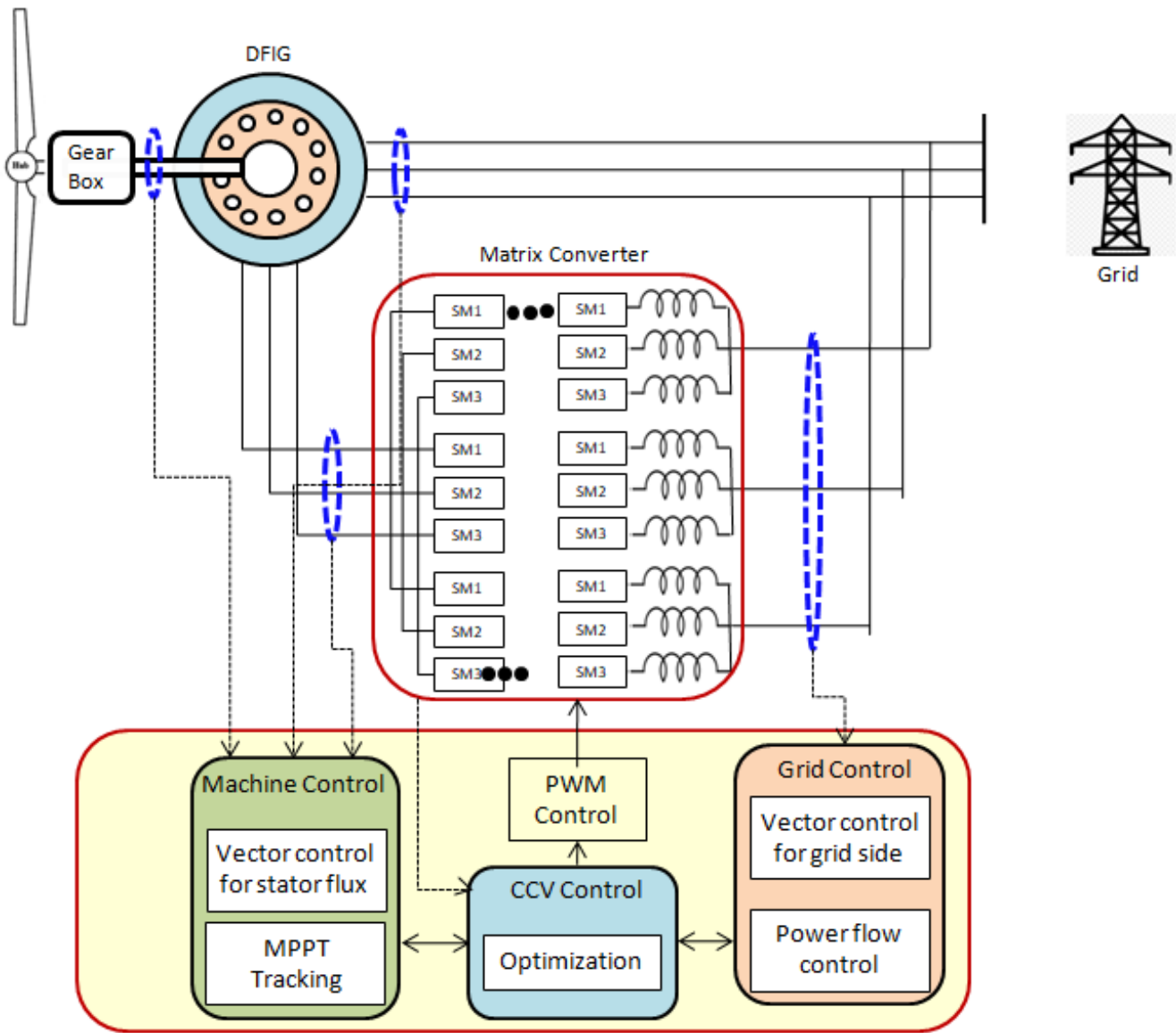

Figure 1. Diagram of the studied system

\section{MODELLING OF WIND ENERGY CONVERSION SYSTEM}

\subsection{Multilevel matrix converter}

The model of multi-level matrix converter is expressed using the Power-Capacitor Voltage model and Voltage-Current model. The structure of the matrix converter is shown in Fig. 2. The obtained values are then articulated using double $\alpha \beta 0$ transform based on the articles in [28, 29]. It is defined as:

$$
\left[X_{\alpha \beta 0}\right]=[C]\left[X_{a b c}\right][C]^{t}
$$

where $[\mathrm{C}]$ and the subscript represent the Clarke transform and natural coordinates, respectively. Double $\alpha \beta 0$ transform offers advantages, like the decoupling of converter current and voltage and also reduction of complexity $[30,31]$.

The main advantage of the voltage- and current-model of MLMC is to allow control of the active and reactive power independently owing to the uncoupled input and output of MLMC [31]. The application of double $\alpha \beta 0$ transform on the voltage and current of this model is based on [30] is given as:

$$
\sqrt{3}\left[\begin{array}{ccc}
0 & 0 & 0 \\
0 & 0 & 0 \\
v_{m \alpha} & v_{m \beta} & 0
\end{array}\right]=L_{c} \frac{d}{d t}\left[\begin{array}{ccc}
i_{\alpha \alpha} & i_{\beta \alpha} & i_{0 \alpha} \\
i_{\alpha \beta} & i_{\beta \beta} & i_{0 \beta} \\
i_{\alpha 0} & i_{\beta 0} & i_{00}
\end{array}\right]+\left[\begin{array}{ccc}
v_{\alpha \alpha} & v_{\beta \alpha} & v_{0 \alpha} \\
v_{\alpha \beta} & v_{\beta \beta} & v_{0 \beta} \\
v_{\alpha 0} & v_{\beta 0} & v_{00}
\end{array}\right]+\sqrt{3}\left[\begin{array}{ccc}
0 & 0 & v_{g \alpha} \\
0 & 0 & v_{g \beta} \\
0 & 0 & 0
\end{array}\right]+\left[\begin{array}{ccc}
0 & 0 & 0 \\
0 & 0 & 0 \\
0 & 0 & 3 v_{n}
\end{array}\right]
$$

where the subscripts ' $\mathrm{m}$ ' and ' $\mathrm{g}$ ' represent the voltage related to the machine and grid side respectively. The currents: $i_{\alpha \alpha}, i_{\beta \alpha}, i_{\alpha \beta}$, and $i_{\beta \beta}$ are the circulating currents, also called the internal current of the converter. Likewise, the currents $i_{0 \beta}$ and $i_{0 \beta}$ dependent only on the output currents while $i_{\beta 0}$ and $i_{\alpha 0}$ dependent on input currents. Furthermore, the voltages $v_{\alpha \alpha}, v_{\beta \alpha}, v_{\alpha \beta}$, and $v_{\beta \beta}$ internal variables, are related to the circulating current. $v_{n}$ is the common-mode voltage. 


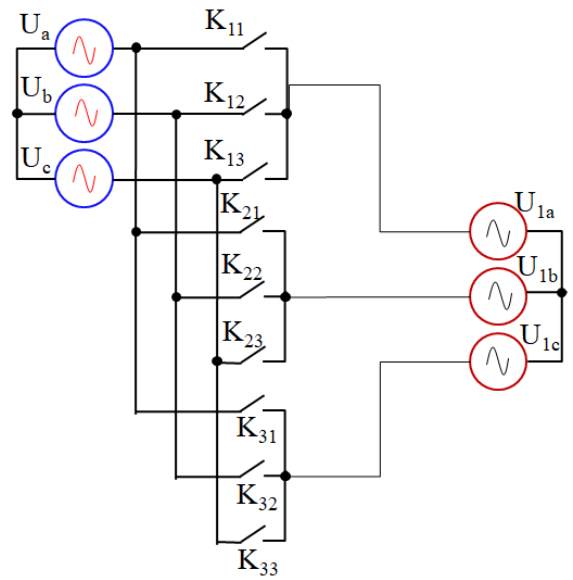

Figue 2. Basic arrangement of matrix converter

\subsection{Power-voltage model of MLMC}

This model permits to relate the power flow of MLMC and the capacitor voltages. The cluster capacitor voltage is the sum of all capacitor voltages inside the cluster. If the capacitor with a continuous voltage $v_{c}^{*}$ has a low ripple than the voltage of cluster capacitor, $\mathrm{Vc}_{\mathrm{mn}}$ is close to $K v_{c}^{*}$. The total power of the cluster $\mathrm{P}_{\mathrm{mn}}$ (since voltage of all the capacitors is equal) is defined as:

$$
P_{m n}=K v_{c}^{*} \frac{d}{d t} V c_{m n}
$$

Double $\alpha \beta 0$ transformation is employed to transform the system. But, as the, cluster capacitor voltage consists of various frequency terms [29] another transform is required: the $\sum \Delta$ transform which is utilized to express the power-cluster capacitor voltage with one oscillating component. Thus, the Double $\alpha \beta 0-\sum \Delta$ transform applied to power-voltage (cluster capacitor voltage) for the proposed MLMC is expressed as:

$$
\left[\begin{array}{c}
X_{1 \alpha}^{\sum v} \\
X_{1 \beta}^{\sum v} \\
X_{2 \alpha}^{\sum v} \\
X_{2 \beta}^{\sum v}
\end{array}\right]=\frac{1}{2}\left[\begin{array}{cccc}
1 & 0 & 0 & 1 \\
0 & 1 & -1 & 0 \\
1 & 0 & 0 & -1 \\
0 & 1 & 1 & 0
\end{array}\right]\left[\begin{array}{l}
X_{\alpha \alpha} \\
X_{\alpha \beta} \\
X_{\beta \alpha} \\
X_{\beta \beta}
\end{array}\right]
$$

Equation 3 rewritten yields the relation below as a new component which expresses power-voltage model of MLMC in $\sum \Delta$ double- $\alpha \beta 0$ coordinates:

$$
K v_{c}^{*} \frac{d}{d t}\left[\begin{array}{ccc}
v_{c 1 \alpha}^{\sum \Delta} & v_{c 1 \beta}^{\sum \Delta} & v_{c 0 \alpha} \\
v_{c 2 \alpha}^{\sum \Delta} & v_{c 2 \beta}^{\sum \Delta} & v_{c 0 \beta} \\
v_{c \alpha 0} & v_{c \beta 0} & v_{c 00}
\end{array}\right] \approx\left[\begin{array}{lll}
P_{1 \alpha}^{\sum \Delta} & P_{1 \beta}^{\sum \Delta} & P_{0 \alpha} \\
P_{2 \alpha}^{\sum \Delta} & P_{2 \beta}^{\sum \Delta} & P_{0 \beta} \\
P_{\alpha 0} & P_{\beta 0} & P_{00}
\end{array}\right]
$$

In equation (5) all the terms except $v_{c 00}$ internal oscillation or voltage variances of cluster capacitor. These oscillations are eliminated by properly regulate the internal power flow of the MLMC and turning the system into a balanced state. The power vectors $P_{1 \alpha \beta}^{\sum \Delta}, P_{2 \alpha \beta}^{\sum \Delta}, P_{\alpha \beta}^{00}$, and $P_{00}^{\alpha \beta}$ are expressed based on [31, 32] as:

$$
\begin{aligned}
& P_{1 \alpha}^{\sum \Delta}=\frac{\overbrace{\left(v_{k \alpha} i_{h \alpha}-v_{h \alpha} i_{k \alpha}\right)+\left(v_{k \beta} i_{h \beta}-v_{h \beta} i_{k \beta}\right)}^{N C C}}{6}+\frac{\frac{\left(v_{k \alpha} i_{2 \alpha}^{\sum \Delta}-v_{k \beta} i_{2 \alpha}^{\sum \Delta}\right)+\left(-v_{h \alpha} i_{2 \alpha}^{\sum \Delta}-v_{h \alpha} i_{2 \beta}^{\sum \Delta}\right)}{\sqrt{6}}-\overbrace{v_{n} i_{1 \alpha}^{\sum \Delta}}^{F C C}}{P_{1 \beta}^{\sum \Delta}=\frac{\left(v_{k \alpha} i_{h \beta}-v_{h \beta} i_{k \alpha}\right)-\left(v_{k \beta} i_{h \alpha}-v_{h \alpha} i_{k \beta}\right)}{6}+\frac{\left(v_{k \alpha} i_{2 \beta}^{\sum \Delta}-v_{k \beta} i_{2 \alpha}^{\sum \Delta}\right)+\left(-v_{h \alpha} i_{2 \beta}^{\sum \Delta}-v_{h \alpha} i_{2 \alpha}^{\sum \Delta}\right)}{\sqrt{6}}-v_{n} i_{1 \alpha}^{\sum \Delta}} \\
& P_{2 \alpha}^{\sum \Delta}=\frac{\left(v_{k \beta} i_{h \alpha}-v_{h \alpha} i_{k \beta}\right)+\left(v_{k \beta} i_{h \beta}-v_{h \beta} i_{k \beta}\right)}{6}+\frac{\left(v_{k \alpha} i_{1 \alpha}^{\sum \Delta}-v_{k \beta} i_{1 \beta}^{\sum \Delta}\right)+\left(-v_{h \alpha} i_{2 \alpha}^{\sum_{2} \Delta}+v_{h \alpha} i_{1 \beta}^{\sum \Delta}\right)}{\sqrt{6}}-v_{n} i_{2 \alpha}^{\sum \Delta} \\
& P_{2 \beta}^{\sum \Delta}=\frac{\left(v_{k \beta} i_{h \beta}-v_{h \beta} i_{k \beta}\right)+\left(v_{k \beta} i_{h \alpha}-v_{h \alpha} i_{k \beta}\right)}{6}+\frac{\left(v_{k \alpha} i_{1 \beta}^{\sum \Delta}-v_{k \beta} i_{1 \alpha}^{\sum \Delta}\right)+\left(v_{h \alpha} i_{1 \beta}^{\sum \Delta}+v_{h \beta} i_{1 \alpha}^{\sum \Delta}\right)}{\sqrt{6}}-v_{n} i_{2 \beta}^{\sum \Delta}
\end{aligned}
$$


Where * represent the complex conjugate of the sinusoidal variables. Similarly, NCC, SCC, and FCC represent the non-controllable components, semi-controllable components, and full controllable components, respectively.

\subsection{Model of DFIG}

Nowadays, wind energy conversion systems with doubly-fed induction generator (DIFG) are common $[33,34]$. The rotating frame called the dq frame of DIFG (stator and rotor) is given in equations (1) \& (2). The stator voltage is noted as $\left(\mathrm{V}_{\mathrm{sdq}}\right)$ and the direction of flow as $\left(\varphi_{s d q}\right)$. The rotor dq frame corresponding to current and voltage are termed as $i_{r d q}$ and $V_{r d q}$. The other machine parameters namely the stator inductance $\left(\mathrm{S}_{\mathrm{L}}\right)$, stator resistance $\left(S_{r}\right)$, rotor resistance $\left(R_{r}\right)$, rotor inductance $\left(R_{L}\right)$, mutual inductance $\left(M_{L}\right)$, the time constant of the stator $(\tau)$, and leakage coefficient of the stator $(\sigma)$, are also noted. The slip angle $\left(\varphi_{s l}\right)$ obtains the vector $V_{r d q}=$

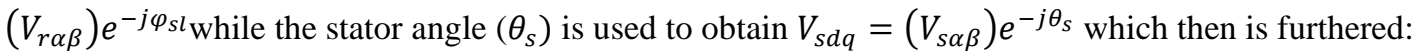

$$
\begin{gathered}
{\left[\begin{array}{c}
V_{s d} \\
V_{s q}
\end{array}\right]=\frac{R_{s}}{L_{s}}\left[\begin{array}{c}
\varphi_{s d} \\
\varphi_{s q}
\end{array}\right]+\frac{d}{d t}\left[\begin{array}{c}
\varphi_{s d} \\
\varphi_{s q}
\end{array}\right]+\omega_{s}\left[\begin{array}{c}
-\varphi_{s d} \\
\varphi_{s q}
\end{array}\right]-R_{s} \frac{L_{m}}{L_{s}}\left[\begin{array}{c}
i_{r d} \\
i_{r q}
\end{array}\right]} \\
{\left[\begin{array}{c}
V_{r d} \\
V_{r q}
\end{array}\right]=S_{R}\left[\begin{array}{c}
i_{r d} \\
i_{r q}
\end{array}\right]+\sigma R_{L}\left[\begin{array}{c}
i_{r d} \\
i_{r q}
\end{array}\right]+\frac{M_{L}}{s_{L}} \frac{d}{d t}\left[\begin{array}{c}
\varphi_{s d} \\
\varphi_{s q}
\end{array}\right]+\omega_{s l} \sigma R_{L}\left[\begin{array}{c}
-i_{r q} \\
i_{r d}
\end{array}\right]+\omega_{s l} \frac{M_{L}}{s_{L}}\left[\begin{array}{c}
-\varphi_{s q} \\
\varphi_{s d}
\end{array}\right]}
\end{gathered}
$$

The electrical torque of the DFIG is solved using the Clarke Transformation:

$$
E_{T}=d_{(\alpha \beta)} p l \frac{M_{L}}{S_{L}}\left(\varphi_{s q} i_{r d}-\varphi_{s d} i_{r q}\right)
$$

\section{POWER LOSS, COST AND RELIABILITY MODEL OF MLMC}

\subsection{Model of power loss}

The power devices used in the submodules produce power loss. It has been classified into switching loss and conduction loss. The average power loss for a particular duration is expressed based on [38] as:

$$
\left.\begin{array}{l}
P_{L C I}=V_{F I} I_{A C I}+r_{I} I_{A C I}^{2} \\
P_{L C D}=V_{F D} I_{A C D}+r_{D} I_{A C D}^{2} \\
P_{L S I}=f_{S}\left(E_{L N}+E_{L O}\right)+\frac{V_{C} I_{A S I}}{I_{R} V_{R}} \\
P_{L S D}=f_{S} E_{R D} \cdot \frac{V_{C} I_{A S D}}{I_{R} V_{R}}
\end{array}\right\}
$$

Where $\mathrm{P}_{\mathrm{LCI}}$ and $\mathrm{P}_{\mathrm{LCD}}$ represent the conduction loss at IGBT and diode, and $\mathrm{P}_{\mathrm{LSI}} \& \mathrm{P}_{\mathrm{LSD}}$ are switching loss of IGBT and diode, respectively. Likewise, $\mathrm{V}_{\mathrm{FI}}$ and $\mathrm{V}_{\mathrm{FD}}$ are the zero current forward voltage drop in IGBT and diode: $\mathrm{I}_{\mathrm{ACD}}$ and $\mathrm{I}_{\mathrm{ACI}}$ are the average current in conduction mode of diode and IGBT; and $\mathrm{I}_{\mathrm{ASD}}$ and $\mathrm{I}_{\mathrm{ASI}}$ are the average currents in switching mode of diode and IGBT. Similarly, $\mathrm{r}_{\mathrm{D}}$ and $\mathrm{r}_{\mathrm{I}}$ are the on state resistance of diode and IGBT; $f_{\mathrm{S}}$ is the switching frequency; $\mathrm{E}_{\mathrm{LN}}$ and $\mathrm{E}_{\mathrm{LO}}$ are the energy loss in the ON and OFF state of IGBT; $E_{R D}$ is the reverse energy recovery of the diode; $I_{R}$ and $V_{R}$ are the rated current and voltage of the power module; and $\mathrm{V}_{\mathrm{C}}$ is the capacitor voltage.

The right and left arm of the bridge used in the MLMC are shown in Fig. 3. The output voltage of the full-bridge under conduction mode is shown on the right side of Fig. 3(b). Similarly, the output characteristics of the full-bridge submodule used in MLMC is listed in Table 1. The conduction of the complementary arm is defined as mode $0\left(\mathrm{~V}_{\text {cap }}\right)$ and mode $1\left(\mathrm{~V}_{\text {cap }}\right)$. To generate two voltage levels, two modulating signals $S_{L}(\omega t)=$ $\left(1-m_{a} \sin (\omega t)\right) / 2$ and $S_{R}(\omega t)=\left(m_{a} \sin (\omega t)-1\right) / 2$ are assigned for the full-bridge module used in the MLMC thereby achieving additional even loss distribution [38].
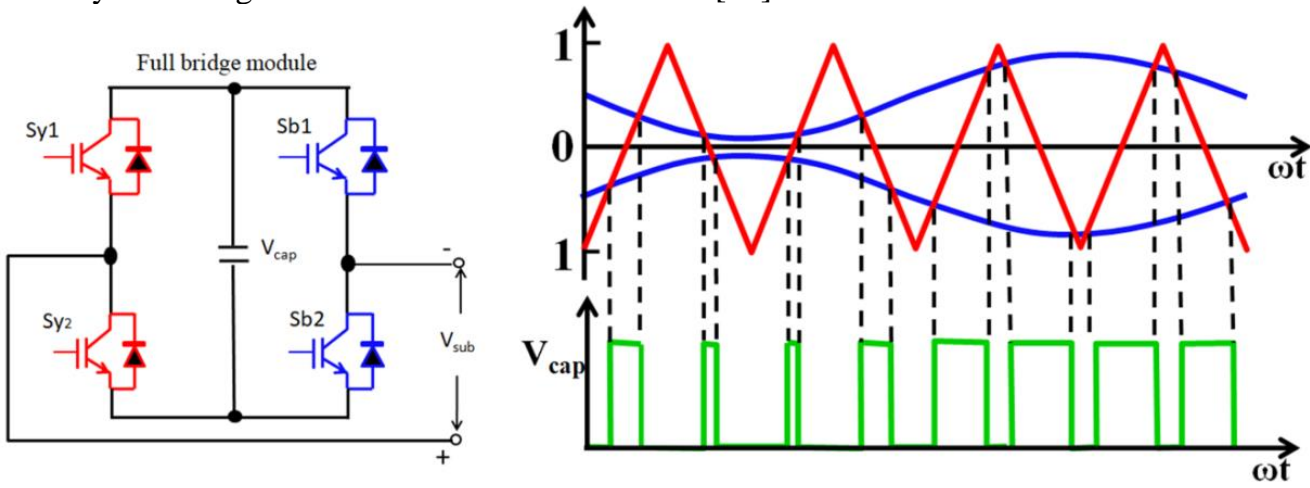

Figure 3. Full bridge submodule and the corresponding output 
The duty cycles of the devices used in the full bridge module is expressed based on [37] as:

$$
\begin{aligned}
& D_{1}(\omega t)=\left[1-m_{a} \sin (\omega t)\right] / 2 \\
& D_{2}(\omega t)=\left[1+m_{a} \sin (\omega t)\right] / 2 \\
& D_{3}(\omega t)=\left[3-m_{a} \sin (\omega t)\right] / 4 \\
& D_{4}(\omega t)=\left[1+m_{a} \sin (\omega t)\right] / 4
\end{aligned}
$$

Table 1. Output characteristics of full bridge submodule used in MLMC

\begin{tabular}{lll}
\hline \multicolumn{2}{l}{ Full Bridge submodule } & $\mathrm{V}_{\mathrm{SM}}$ \\
\cline { 1 - 2 } Left arm & Right arm & \\
\hline 0 & 0 & 0 \\
0 & 1 & $-\mathrm{V}_{\mathrm{c}}$ \\
1 & 0 & $\mathrm{~V}_{\mathrm{c}}$ \\
1 & 1 & 0 \\
\hline
\end{tabular}

Where $d_{1}$ and $d_{2}$ are the duty cycles of the power devices $T_{1}$ and $T_{2}$ used in the full-bridge module. $D_{3}$ is used for $T_{1}$ or $T_{4}$, and $D_{4}$ is used for $T_{2}$ or $T_{3}$, respectively. Based on equations (13) and (14) the simplified power loss model is expressed as:

$$
\begin{gathered}
P_{L C I}=\frac{1}{2 \pi} \int_{\beta_{1}}^{\beta_{2}}\left\{\left[V_{F I} i_{a}(\omega t)+r_{I} i_{a}^{2}(\omega t)\right] d_{I}(\omega t)\right\} d \omega t \\
P_{L C I}=\frac{1}{2 \pi} \int_{\beta_{3}}^{\beta_{4}}\left\{\left[V_{F D} i_{a}(\omega t)+r_{D} i_{a}^{2}(\omega t)\right] d_{D}(\omega t)\right\} d \omega t \\
P_{L S I}=\frac{f_{S} V_{d c}\left(E_{L N}+E_{L O}\right)}{2 \pi N I_{R} V_{R}} \int_{\beta_{1}}^{\beta_{2}} i_{a}(\omega t) d \omega t \\
P_{L S D}=\frac{f_{S} V_{d c} E_{R D}}{2 \pi N I_{R} V_{R}} \int_{\beta_{3}}^{\beta_{4}} i_{a}(\omega t) d \omega t
\end{gathered}
$$

Where $\beta_{1}, \beta_{2}$, and $\beta_{3}, \beta_{4}$ represent the IGBT conduction interval and diode conduction interval, respectively. The total power loss is estimated using equation (10) for the full-bridge module used in MLMC. However, the redundant modules of the converter also increase the total conduction loss.

Table 2. Rate of failure of components of converter module

\begin{tabular}{llll}
\hline Circuit & Component & Rate of failure & No. \\
\hline Submodule & Capacitor & 0.0000876 & 1 \\
& IGBT module & 0.0003504 & $2 / 4$ \\
Power circuit & Custom ICs and circuit & 0.0014279 & 1 \\
\hline
\end{tabular}

\subsection{Model of reliability}

The reliability of the converter depends on the rate of failure of the devices in the submodule and the operating time. The failure probability of MLMC is given as:

$$
R(t)=e^{-\gamma t}
$$

Where ' $t$ ' is the operating time, and ' $\gamma$ ' is the rate of failure. The rate of failure of the components of the submodule presented in the converter (refer to Fig. 1), contained in a driver PCB board. The rate of failure of the components is presented in Table 2 [13]. More to it, the rate of failure of the capacitor and IGBT due to voltage fluctuation and thermal stress are articulated in the acceleration factor and is defined as:

$$
\begin{aligned}
& \gamma_{I G}=\gamma_{I G} T_{I G} A_{F} E_{S} F_{E} P_{F} \\
& \gamma_{c}=\gamma_{c} T_{c} A_{c} E_{c} P_{c}
\end{aligned}
$$

Where $\gamma_{c}$ and $\gamma_{I G}$ are the rates of failure of the capacitor and IGBT module at rated running condition. $T_{C}$ and $T_{I G}$ are the temperature factors of the capacitor and IGBT module. $A_{F}, E_{S}, F_{E}$ and $P_{F}$ stand for application factor, electric stress factor, environmental factor, and power rating factor respectively. Similarly, $A_{c}, E_{c}$, and $P_{c}$ denotes the capacitor factor, series resistance factor, and voltage stress factor respectively.

The MLMC must have the capacity to manage potential faulty submodules or else it is deemed unreliable. Hence, this situation calls for maintenance. Therefore, if the numbers of the faulty half-bridge and full-bridge are denoted as ' $a$ ' and ' $b$ ' respectively, ' $a$ ' may be more than the number of redundant half-bridge submodules per arm (NRH) but ' $b$ ' should not be exceed the number of redundant full-bridge submodule (NRF). This reliability then comprises two elements: $a \geq N_{R H}$ and $b \leq N_{R F}$, the highest value of ' $\mathrm{b}$ ' depends on ' $\mathrm{a}$ ', and is represented as $\mathrm{b}_{\max }(\mathrm{a})$. Accordingly, $\mathrm{HB}$ is the highest value to meet: $\mathrm{N}_{\mathrm{FB}}+N_{R F}-\mathrm{b}_{\max }(\mathrm{a}) \geq$ $\sqrt{3} / 4 \times\left[\mathrm{M}-a-\mathrm{b}_{\max }(\mathrm{a})\right]$ and the reliability of this element is expressed as: 


$$
r_{1}=\sum_{a=0}^{N_{R H}}\left\{\sum_{b=0}^{\mathrm{b}_{\max }(\mathrm{a})} C_{s m+N_{R H}}^{a}\left[\left(1-r_{H}\right)^{a} \cdot r_{H}^{N_{H B}+N_{R H}-a}\right] \times C_{s m+N_{R H}}^{a}\left[\left(1-r_{F}\right)^{a} \cdot r_{F}^{N_{F B}+N_{R F}-b}\right]\right\}
$$

where $\mathrm{M}=\mathrm{N}+\mathrm{N}_{\mathrm{RH}}+\mathrm{N}_{\mathrm{RF}}, \mathrm{N}$ being the number of submodules per arm. Similarly, $\mathrm{N}_{\mathrm{HB}}$ and $\mathrm{N}_{\mathrm{FB}}$ are the numbers of the half-bridge submodule and full-bridge submodule respectively.

1) $a<N_{R H}$ and $b \leq N_{R F}+N_{R H}-a$. The number of fit submodule should obey the relation: $N_{R F} \leq$ $\mathrm{N}_{\mathrm{FB}} \leq N_{H B}$. And should be greater than $\mathrm{N}$. The reliability then is again expressed as:

$$
r_{2}=\sum_{a=N_{R H}+1}^{N_{R H}+N_{R F}}\left\{\sum_{b=0}^{N_{R H+N_{R F}}-a} C_{s m+N_{R H}}^{a}\left[\left(1-r_{H}\right)^{a} \cdot r_{H}^{N_{H B}+N_{R H}-a}\right] \times C_{s m+N_{R H}}^{a}\left[\left(1-r_{F}\right)^{a} \cdot r_{F}^{N_{F B}+N_{R F}-b}\right]\right\}
$$

Finally, the reliability of MLMC is expressed as: $R E_{M L M C}=r_{1}+r_{2}$.

The principal distinction between the reliability model of the proposed MLMC and the model presented in [7] is the fault ride-through capacity. The reliability model of [7] does not take fault ride-through capacity into consideration. The estimated reliability is almost equal for both the methods: in [7] and the proposed technique - provided that the value of $N_{\mathrm{RH}}$ is small. However, if the value of $N_{\mathrm{RH}}$ becomes greater as a result of aforementioned constraints of fault ride-through capacity, the reliability gets affected.

\subsection{Model of cost}

The cost of the proposed multilevel matrix converter for the wind energy conversion system is split into initial and functional outlays [24]. Fig. 4 shows that the initial cost comprises of the submodule and auxiliary cost while the functional cost comprises of power loss cost. The auxiliary cost viz. the cost of the IGBT module and the capacitor is considered $10 \%$ of the submodule cost [13]. The cost of the bypass switch and grading resistor is neglected in the initial cost [19].

While the initial cost of the MLMC is directly proportional to the power rating of the converter, the submodule cost, however, is inversely proportional to $N$. The reliability increases if $\mathrm{N}$ value increases. The practical requirement is achieved by limiting the value of $\mathrm{N}$ between 7 and 20. Various parameters of the wind energy conversion system with an application of $\mathrm{N}=7$ value is listed in Table 3.For the IGBT module, SEMIKRON SKiiP 11NAB066V1is preferably selected due to its 50\% less requirement of operating voltage and voltage margin. The wind speed and cut-in speed of the wind turbine is $14 \mathrm{~m} / \mathrm{s}$ and $5 \mathrm{~m} / \mathrm{s}$ with the rated frequency of $10 \mathrm{~Hz}$. From an engineering point of view, the package of the chip and its size can be owed to the thermal and electrical behavior of the device.

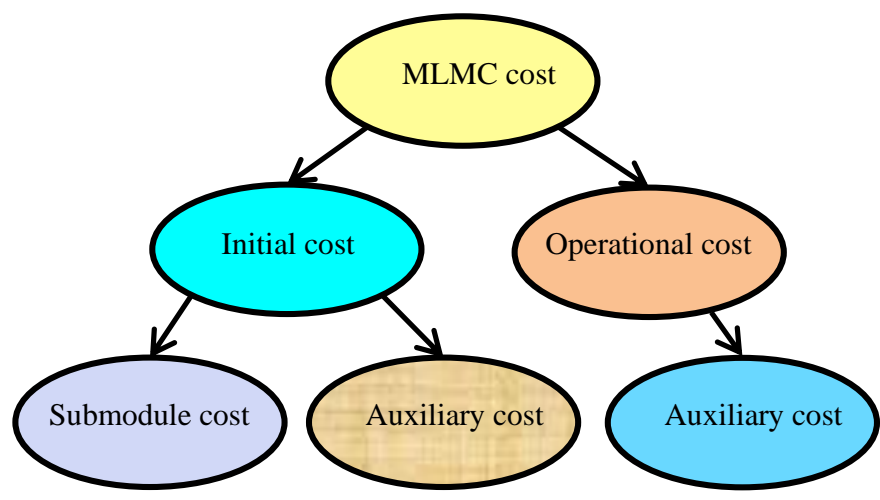

Figure 4. Various components of cost of MLMC for wind energy conversion system

Therefore, the cost of the IGBT module is expressed as:

$$
I G_{\text {cost }}=\sum_{n} D_{\text {chip }} P_{\text {chip }}+\sum P_{k}
$$

Where $\mathrm{D}_{\text {chip }}, \mathrm{P}_{\text {chip }}$, and $\mathrm{P}_{\mathrm{k}}$ are the value per chip area, chip area, and price of pack, respectively.

Table 3 . Various parameters of wind energy conversion system by applying $\mathrm{N}=7$

\begin{tabular}{llll}
\hline MLMC & & Submodule & \\
\hline Rated voltage & $\mathrm{V}_{\mathrm{R}}=10 \mathrm{kV}$ & Rated voltage of IGBT & $\mathrm{V}_{\mathrm{G}}=4.5 \mathrm{kV}$ \\
Active power & $\mathrm{P}_{\mathrm{A}}=9 \mathrm{MW}$ & Submodule capacitance & $\mathrm{C}_{\text {sub }}=20 \mathrm{mF}$ \\
$\begin{array}{l}\text { DC voltage } \\
\text { Inductance of the }\end{array}$ & $\mathrm{V}_{\mathrm{dc}}=17 \mathrm{kV}$ & Switching frequency & $\mathrm{f}_{\mathrm{s}}=510 \mathrm{~Hz}$ \\
arm & $\mathrm{L}_{\mathrm{arm}}=4.9 \mathrm{mH}$ & IGBT module rated current & $\mathrm{I}_{\mathrm{GR}}=0.85 \mathrm{kA}$ \\
\hline
\end{tabular}


Furthermore, the cost of a film capacitor is expressed as:

$$
\sum C_{\text {cost }}=x+y \cdot V_{c}+z \cdot C_{\text {sub }}
$$

Where $\mathrm{x}=1.02$ Euro, $\mathrm{y}=0.05 \mathrm{Euro} / \mathrm{V}$, and $\mathrm{z}=2.43 \mathrm{Euro} / \mathrm{mF}$ [38]. $\mathrm{C}_{\text {sub }}$ and $\mathrm{V}_{\mathrm{c}}$ are the capacitance of the submodule and the rated voltage of the capacitor. The ripple of the submodule of certain converter topology is required to be limited to determine $\mathrm{C}_{\text {sub}}$ : the voltage ripple affects the energy control method. Furthermore, a few precise strategies are developed for limiting the voltage ripple of the converters. It will change the control method thereby resulting in the change in power loss. Hence, it should be necessarily implicated in the cost estimation. In this paper, the cost framework of a multilevel converter is provided in a standard functionality without considering a particular control technique. Therefore, the percentage of ripple (peak-to-peak) of the submodule $(\alpha)$ capacitor voltage is expressed as:

$$
\alpha=\frac{I_{m} N}{2 C_{\text {sub }} \omega_{r} V_{d}}\left[1-\left(\frac{m_{a} \cos \varphi}{2}\right)^{2}\right]^{3 / 2}(\mathrm{rad} / \mathrm{s})
$$

where $\omega_{r}$ represents the angular frequency of the doubly-fed induction generator. The value of $\mathrm{V}_{\mathrm{d}}$, for the study, is chosen as $18 \mathrm{kV}$ and $\alpha$ is limited to $8 \%$. The capacitance value then is chosen higher than previously calculated with N. $C_{s u b}, \omega_{r}$, and $V_{d}$ are inversely proportional to $\alpha$, but proportional to $I_{m}$ and $N$. The total loss $\left(\mathrm{T}_{\mathrm{L}}\right)$ of MLMC based on equation (3) along with the wind power cost $\left(\mathrm{W}_{\mathrm{C}}\right)$ is assumed as $0.10 \mathrm{Euro} / \mathrm{kWh}$ and the Baseline Capacity Factor $(\mathrm{BCF})$ as 0.375 . Also, the operating year of the device $\left(\mathrm{OY}_{\mathrm{d}}\right)$ is chosen as 20 years and the function of the turbine per day (FT) as $9100 \mathrm{~h}$. Then, the power loss cost is expressed as:

$$
\sum P L=T_{L} \times W_{c} \times O Y_{d} \times B C F \times F T
$$

Therefore, the total cost of MLMC is defined as:

$$
\sum C_{M L M C}=\sum \text { init }+\sum P L
$$

The initial cost model of the capacitors and IGBT modules are taken from [13,38]. Validation of the power loss model is carried out in [24].

\subsection{Multi-objective optimization model}

The main aim of topology optimization of MLMC is to achieve the lowest amount of cost and the highest amount of reliability. It is expressed as:

$$
\left.\begin{array}{c}
\min _{1}=C_{M L M C}\left(\mathrm{~N}+\mathrm{N}_{\mathrm{RH}}+\mathrm{N}_{\mathrm{RF}}\right) \\
\max _{2}=\sum R E_{M L M C}\left(\mathrm{~N}+\mathrm{N}_{\mathrm{RH}}+\mathrm{N}_{\mathrm{RF}}\right)
\end{array}\right\}
$$

The MLMC should have the capability to manage the DC fault ride through and redundant submodules. Various constraints are defined to optimize the parameters and are given by

$$
\left.\begin{array}{c}
\frac{\sqrt{3} M}{4} \leq\left(\mathrm{N}_{\mathrm{FB}}+N_{R F}\right) \\
0 \leq N_{R F} \leq \mathrm{N}_{\mathrm{FB}} \\
6 \leq N \leq 20 \\
0 \leq N_{R H} \leq N_{H B}
\end{array}\right\}
$$

Likewise, the multi-objective optimization model is given by

$$
\left.\begin{array}{c}
\min _{i}(x), i=1,2, \ldots k \\
\text { s.t } d_{j}(x) \leq 0, \quad q=1,2, \ldots m \\
c_{p}(x)=0, \quad p=1,2, \ldots n
\end{array}\right\}
$$

Where ' $\mathrm{x}$ ' is the decision variable and $S=\left(C_{M L M C},-R E_{M L M C}\right)$. ' $\mathrm{k}$ ' is the number of objective function. ' $\mathrm{D}$ ' and ' $\mathrm{m}$ ' are the inequality constraints and ' $c$ ' and ' $\mathrm{n}$ ' are the equality constraints.

\subsection{Optimal topology of MLMC}

The objective functions of the proposed MLMC model have not offeredthe optimal solution simultaneously, they seem to be contradictoryto each other. Therefore, the Pareto-optimal set (POS) is the optimal solution. POS explicatesa complete relationship between reliability and the cost of MLMC compared withsingle-objective function. As a result, the optimal solution is chosen using a fuzzy membership function or some definiteconstraints. The optimized topology of the proposed MLMC is shown in Fig. 5. 


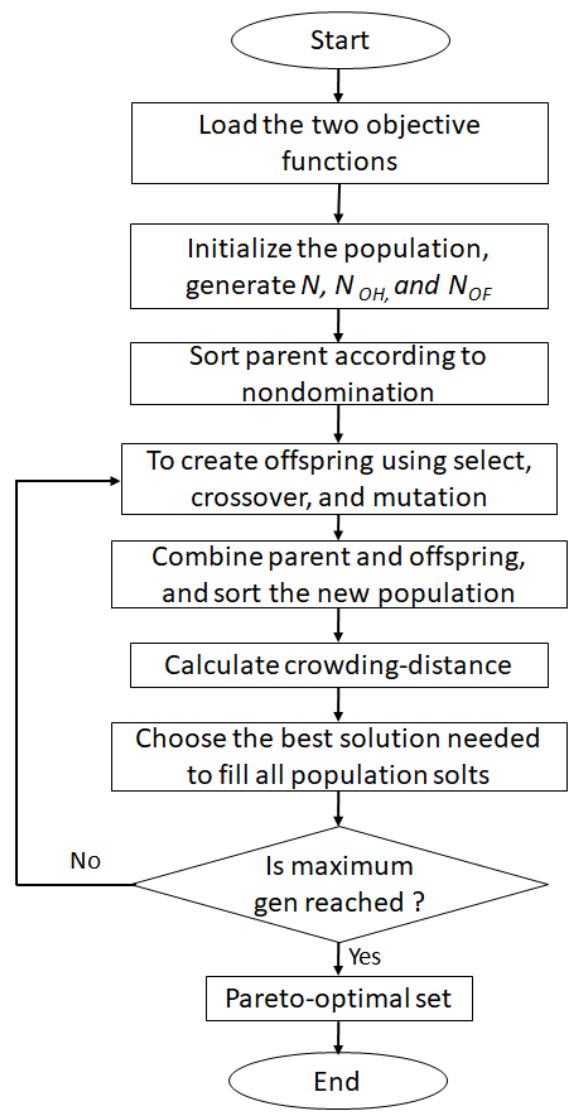

Figure 5. Flow diagram of the proposed multi-objective optimization

The fuzzy membership function is used to select OS for applications with no special requirement; the membership function of the minimum objective is defined as:

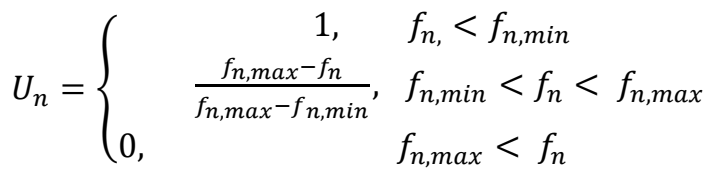

\section{RESULTS AND DISCUSSION}

The simulation was carried out by setting the active reference power $\mathrm{P}_{\text {act }}$ to the optimal mechanical power of the turbine, and the reactive power $\mathrm{P}_{\text {rea }}$ equal to zero. In this study, two different scenarios: fixed speed and variable speed operation, of $9 \mathrm{MW}$ turbine, have been implemented using PLECS software. For the first scenario, the simulation was conducted with a constant wind speed of $10 \mathrm{~m} / \mathrm{s}$. In the second, variable wind velocity was employed for $30 \mathrm{~s}$. Various parameters used in the converter and the machine are listed in Table 4.

Table 4. Various parameters used for simulation

\begin{tabular}{ll}
\hline Machine parameters & Value \\
\hline Nominal power & $9 \mathrm{MW}$ \\
Nominal speed & $1310 \mathrm{RPM}$ \\
Stator voltage & $3.8 \mathrm{kV}$ \\
Capacitor voltage & $900 \mathrm{~V}$ \\
Switching frequency & $0.7 \mathrm{kHz}$ \\
Grid frequency & $50 \mathrm{~Hz}$ \\
Rotor resistance & $25.75 \mathrm{~m} \Omega$ \\
Stator resistance & $26.84 \mathrm{~m} \Omega$ \\
Rotor inductance & $26.11 \mathrm{mH}$ \\
Stator inductance & $25.13 \mathrm{mH}$ \\
Number of cells (per cluster) & 20 \\
Mutual inductance & $24.91 \mathrm{mH}$ \\
Capacitance & $6000 \mu \mathrm{F}$ \\
\hline
\end{tabular}




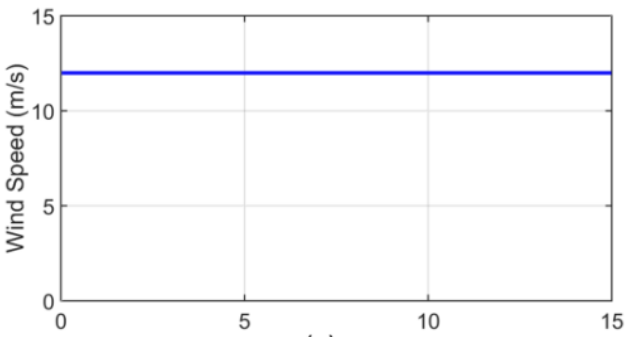

(a)

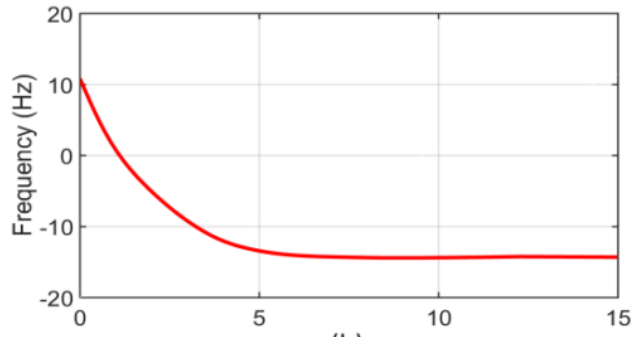

(b)

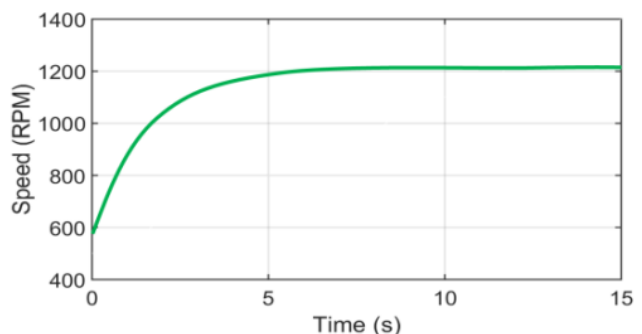

(c)

Figure 6. (a) wind speed for the turbine (b) input frequency (c) Speed of the machine

\subsection{Case 1: Constant speed operation}

In this case, the test was carried out with constant wind speed. Fig. 6(a) shows the fixed wind speed of $12 \mathrm{~m} / \mathrm{s}$ applied in this experiment. Initial conditions such as machine speed, capacitor voltages, and inertia are considered for better converge of the system. Due to the current control of the rotor, the matrix converter tracks the maximum power point of the turbine after a transition period.

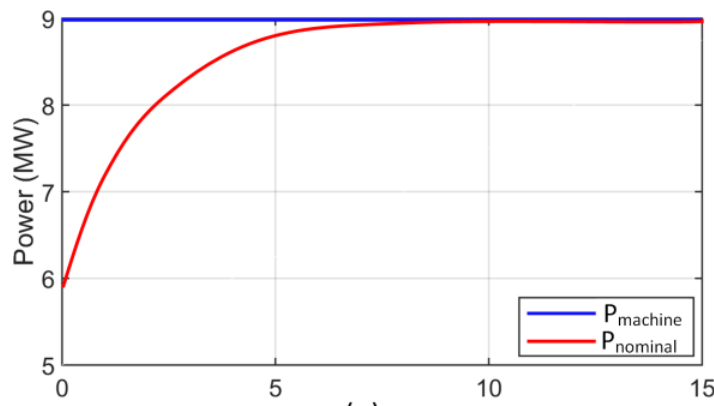

(a)

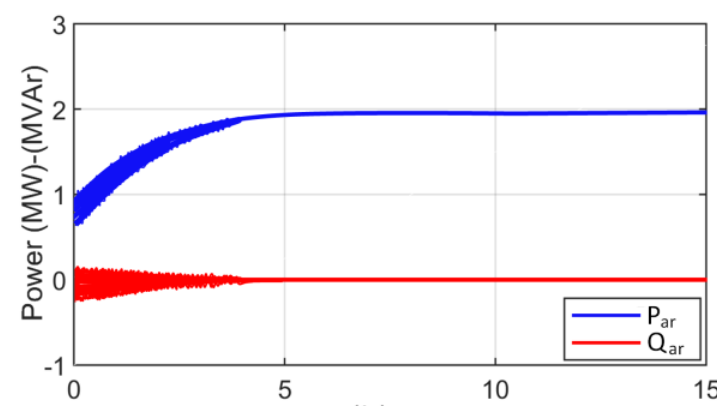

(b)

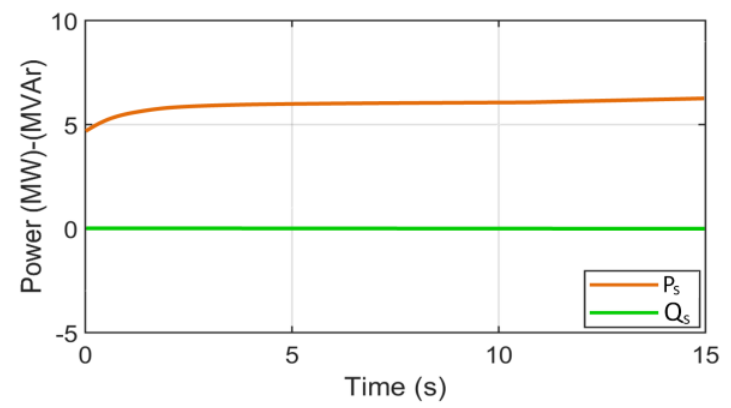

(c)

Figure 7. Total, active, and reactive power of generator (a) Total active power of the generator (b) power flow of active and reactive power of rotor (c) power flow of active and reactive power of stator 


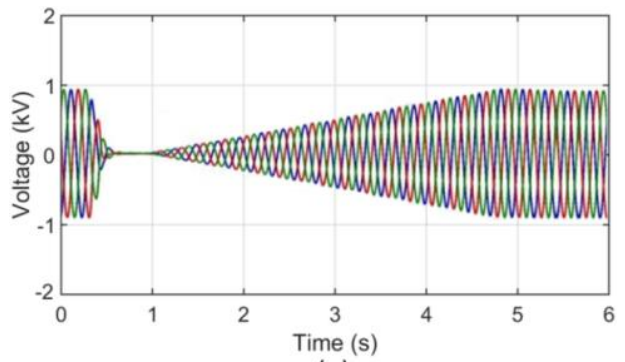

(a)

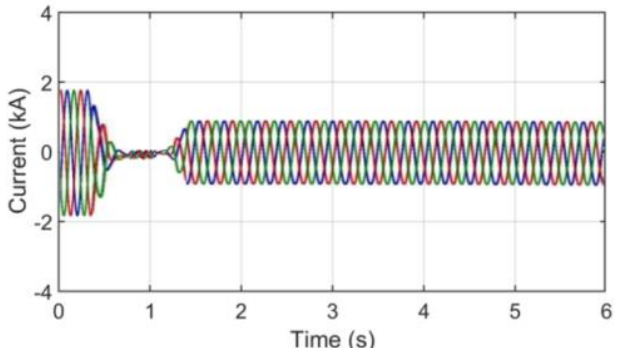

(b)

Figure 8 . The current and voltage of the machine side (a) rotor voltage (b) rotor current

The frequency of the rotor is shown in Fig. 6 (b) which also indicates that the rotor voltage has a frequency of $-16.8 \mathrm{~Hz}$ under steady-state condition. The negative slip of the machine notably resulted in a negative frequency. As a result, it crossed the synchronous speed of 1000 RPM. In this case, the nominal speed of the machine was recorded to be1380 RPM at $t=3.5 \mathrm{~s}$ as shown in Fig. 6 (c).

The operation of the turbine with a maximum power point and the power flow is illustrated in Fig. 7. Fig. 7 (a) points out that the nominal active power $\left(\mathrm{P}_{\text {nominal }}\right)$ of DFIG reaches the steady-state around $7 \mathrm{~s}$. The sum of active power flow of stator $\left(\mathrm{P}_{\mathrm{as}}\right)$ and the active power flow of the rotor $\left(\mathrm{P}_{\mathrm{ar}}\right)$ is equal to the nominal power of the machine under steady-state condition is shown in Fig 7(b) and (c) respectively. . Hence, MOMMC does not consume active power as a result of which the flow of reactive power of both the port is zero. The active power of the rotor and the stator is defined using the relation: $\mathrm{P}_{\mathrm{as}}=$-slip. $\mathrm{P}_{\mathrm{ar}}$. Evidently, the active power of the stator is higher than that of the reactive power of the rotor in absence of reactive power flow under a steady state.

Fig. 8 shows the machine-side current and voltage on the rotor. It is observed that the rotor voltage reached its minimum at $\mathrm{t}=0.85$ with no frequency in the current waveform. This can be attributed to the equalization of speed of the shaft and the synchronous machine.The rotor current on the grid in the posttransient period, on the other side of MOMMC, is shown in Fig. 9. It indicates that the sinusoidal characteristic is achieved at the grid side. The outcome exhibits the exact operation of the proposed MOMMC on the grid side.

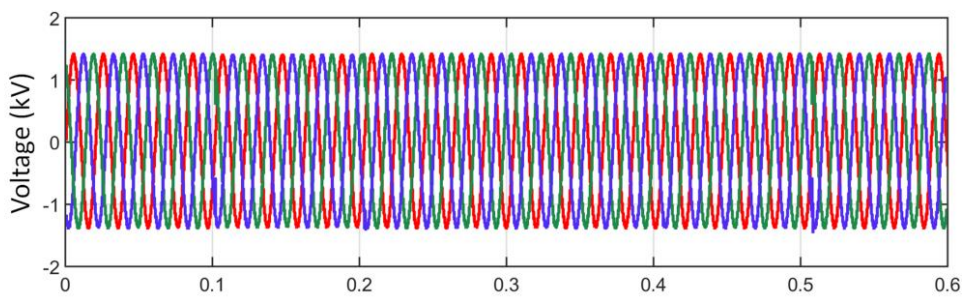

(a)

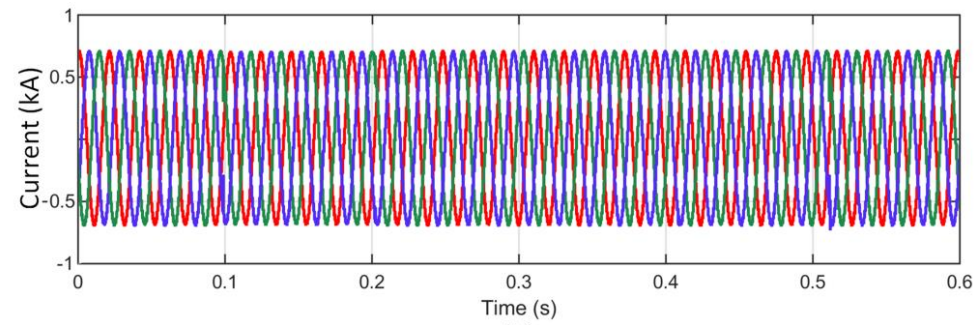

(b) 
Figure 9. The current and voltage of the grid side (a) rotor voltage (b) rotor current

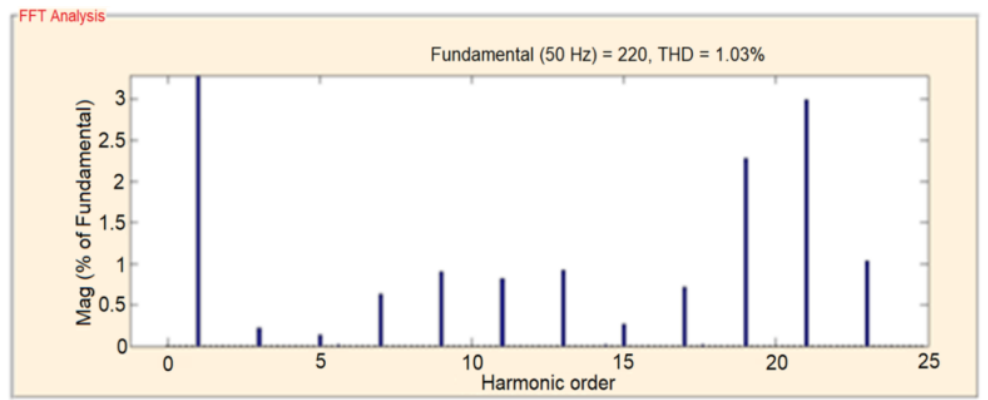

Fig. 10. The harmonic spectrum for gird side voltage (case-1)

The output voltage of optimized multilevel matrix converter for wind energy conversion system and their corresponding Fourier harmonic spectrum for grid side voltage is shown in Fig. 10. The THD of the output current is $1.03 \%$.
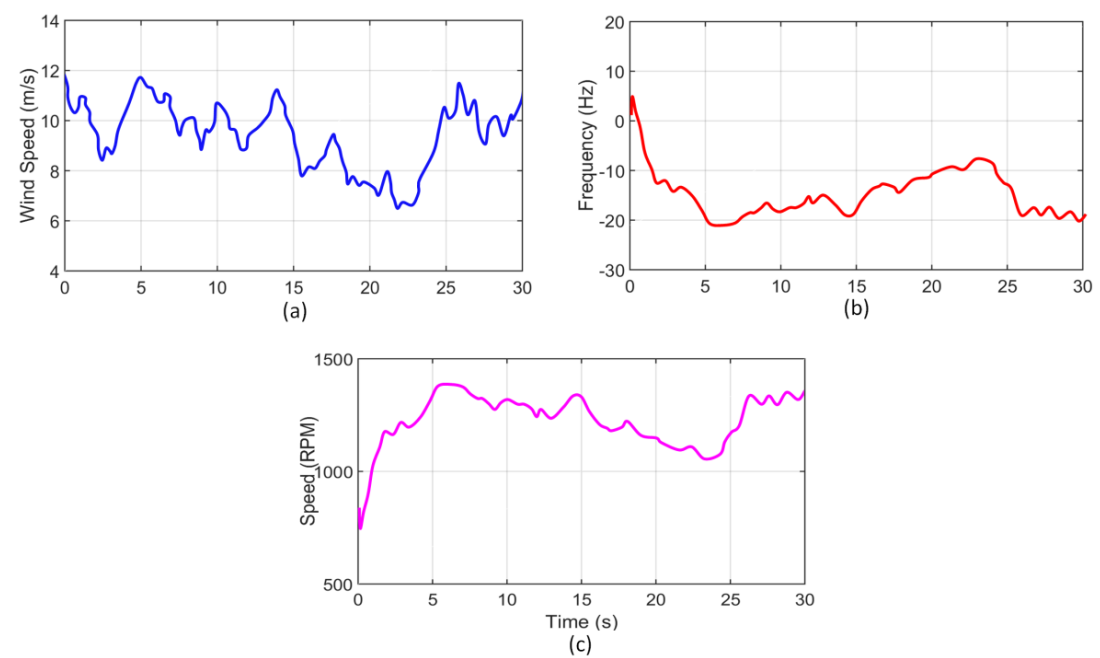

Figure 11. (a) wind speed for the turbine (b) input frequency (c) Speed of the machine

\subsection{Case 2: Variable speed operation}

The proposed model is tested under variable wind speed condition as illustrated in Fig. 11. For this purpose, wind speed variation for $30 \mathrm{~s}$ is taken in Fig. 11(b) signifies that the frequency varied in the range 4 to- $20 \mathrm{~Hz}$ (machine side) due to wind speed variation. Furthermore, the turbine speed is illustrated in Fig. 11(c) which indicates that the machine reached synchronous speed at $t=3.5 \mathrm{~s}$.
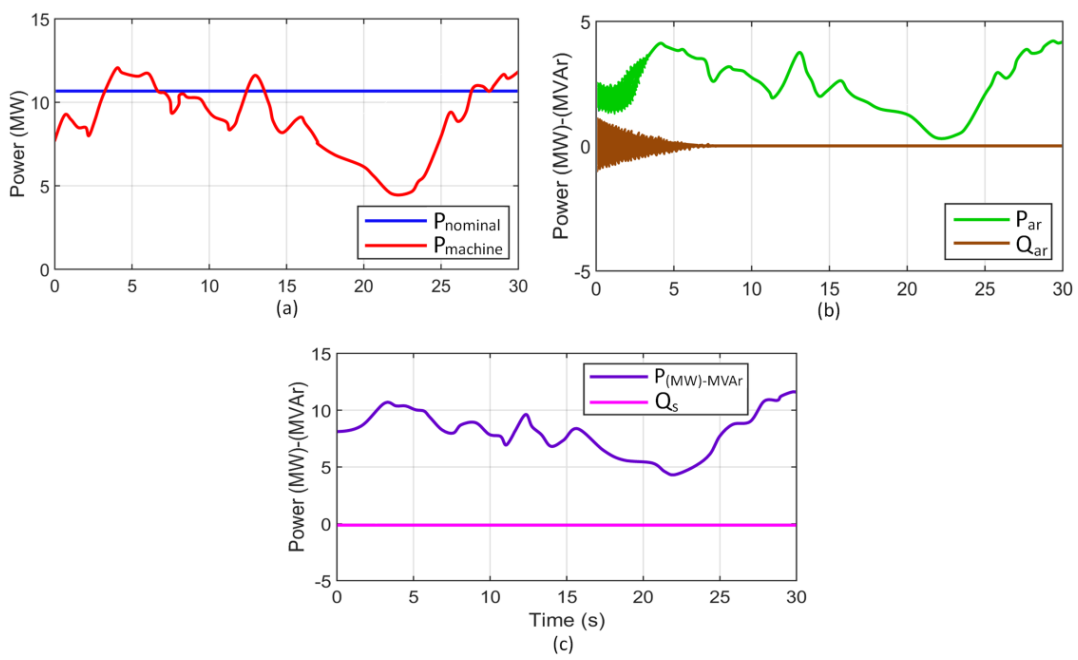
Figure 12. Total, active, and reactive power of generator (a) Total active power of the generator (b) power flow of active and reactive power of rotor (c) power flow of active and reactive power of stator

The combination of DFIG and the proposed multi-objective optimization based multilevel matrix converter generates active power flow under variable speed operation as shown in Fig. 12. Likewise, the nominal power and machine-generated power are shown in Fig. 12(a). The active power flow is always positive and hence the machine generates useful power to the grid as shown in Fig. 12(b).

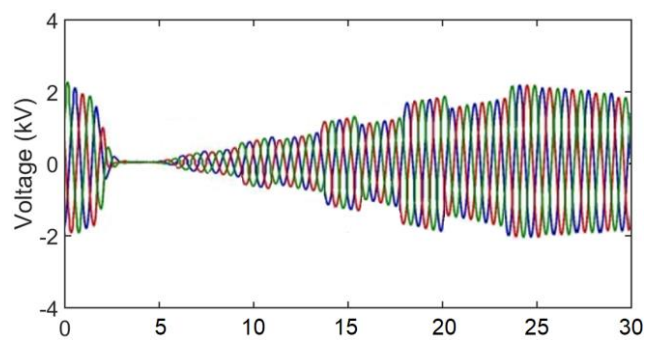

(a)

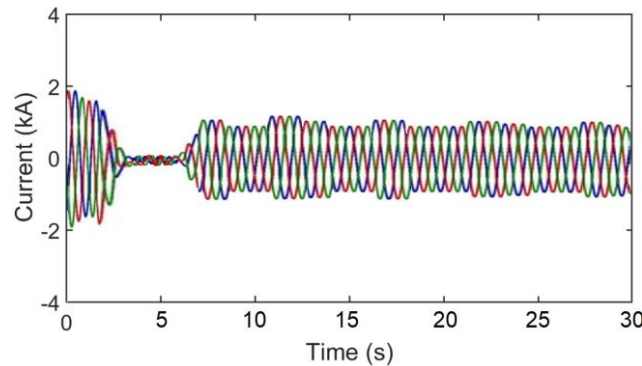

(b)

Figure 13. The current and voltage of the machine side (a) rotor voltage (b) rotor current

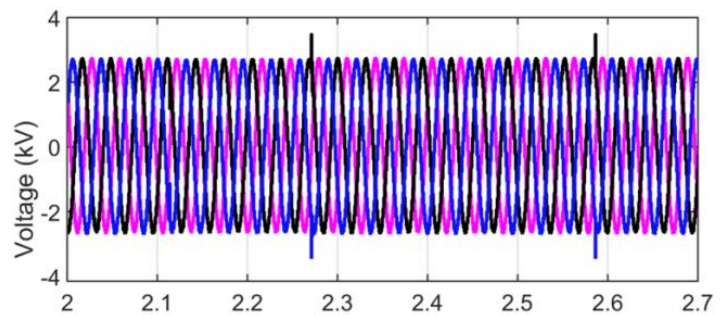

(a)

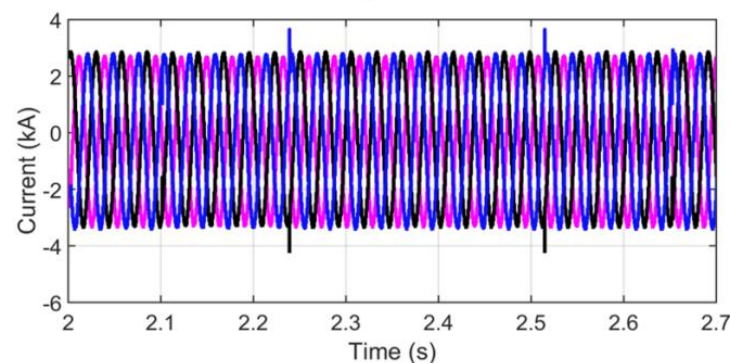

(b)

Figure 14. The current and voltage of the grid side (a) rotor voltage (b) rotor current

At $\mathrm{t}=24 \mathrm{~s}$, the minimum amount of power is generated at the rotor port which is small compared to the stator port power flow (refer Fig. 12(c)). The performance of the proposed MOMMC against the aforementioned model is superior because there is no reactive power flow and the unity power factor is maintained.

The effect on the rotor current and voltage for the proposed MOMMC is shown in Fig. 13. It is observed that the rotor voltage reached its minimum at $\mathrm{t}=0.65$ with no frequency present in the current waveform. The results drawn for variable wind speed are almost similar to the constant wind speed settings. 
The rotor current on the grid for the post-transient period, by using the proposed MOMMC, is shown in Fig. 14. It indicates that the sinusoidal characteristic is achieved at the grid side even when the wind speed varied. The outcome exhibits the predicted operation of the proposed MOMMC on the grid side.

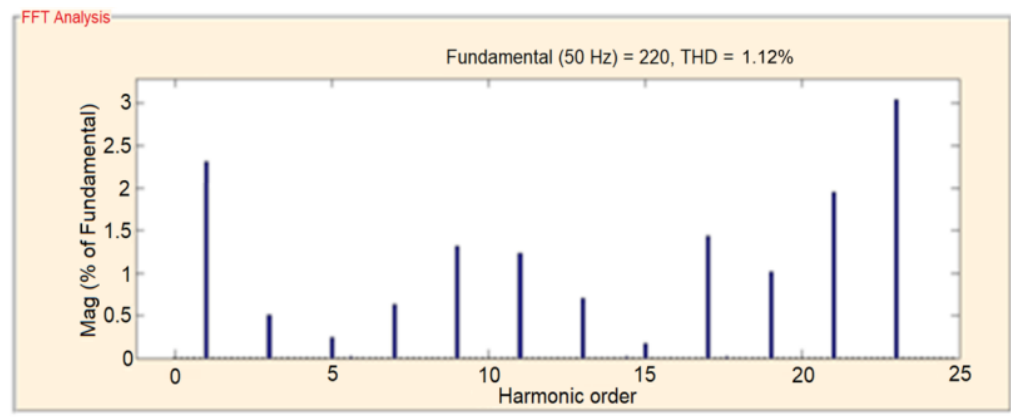

Fig. 15. The harmonic spectrum for gird side voltage (case-2)

The output voltage of optimized multilevel matrix converter for wind energy conversion system and their corresponding Fourier harmonic spectrum for grid side voltage is shown in Fig. 15. The THD of the output current is $1.03 \%$.

\subsection{Comparison results}

The power rating $9 \mathrm{MW}, 1310 \mathrm{rpm}$ is selected for two different cases such as fixed speed operation and variable speed operation. Vaious other parameters of PMSG is listed in Table 4. The cost elements for various parameters define the total cost are shown in Fig. 16. From Fig. 16 one can easily understand that the two cases have some similarities. Despite the choice of transmission technology, purchase, installation, and testing of the offshore wind power system consume half of the total cost. Other cost like unavailability cost has the smallest percentage, the cost of power loss occupy less than 10 percentage, operation and maintenance $(\mathrm{O} \& \mathrm{M}) \operatorname{cost}$ slightly less than $20 \%$.

\section{CONCLUSION}

Multi-objective optimization-based multilevel matrix converter is proposed for wind energy conversion system. Reliability and cost: the two objective functions have been considered in this study. The optimal solution is taken from the Pareto-optimal set. Two different cases: 1) fixed and 2) variable speed, of $9 \mathrm{MW}$ doubly-fed induction generator-based wind energy systems, is considered. Initially, the test is carried out for fixed wind speed. The frequency, speed, and active and reactive power flow of stator and rotor is obtained. Moreover, the rotor voltage and current of the machine side and the grid side are also measured. Further, the variable speed operation of the proposed MOMMC method is carried out for 9 MW doubly-fed induction generators. The frequency; speed; active and reactive power; and the rotor voltage and current of the machine side and the grid side are also measured. The results obtained indicate that the proposed MOMMC method is more suitable for wind energy conversion system.

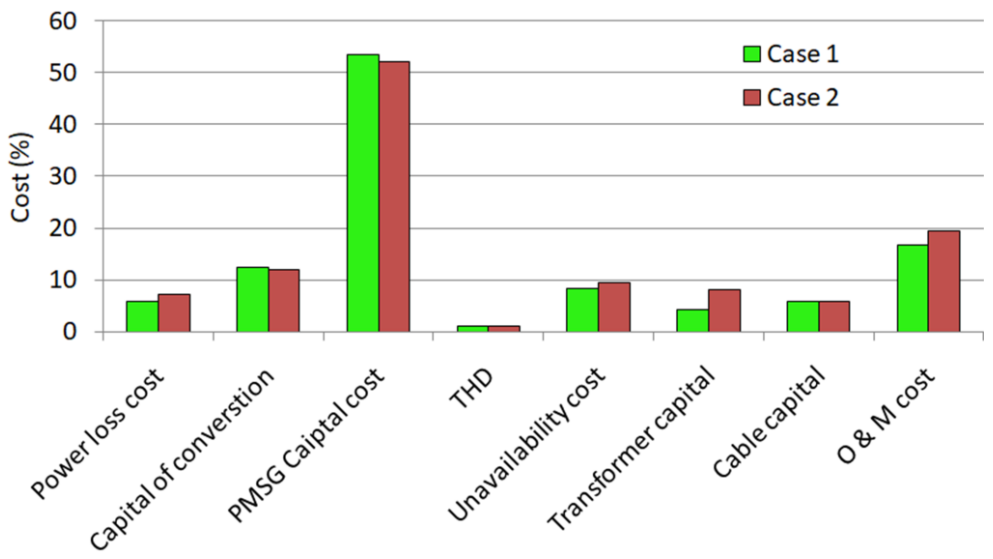

Fig. 16. Cost comparison of two different case studies carried out for the proposed MOMMC 


\section{REFERENCES}

[1] Bonnet, F., Vidal, P., Pietrzak-David, M. Dual direct torque control of doubly fed induction machine. IEEE Trans Ind Electron 2007; 54(5): 2482-90.

[2] Wheeler, PW., Rodriguez, J., Clare, JC., Empringham, L., Weinstein, A. Matrix converter: a technology review. IEEE Trans Ind Electron 2002; 49(2): 276-88.

[3] Simon, O., Mahlein, J., Muenzer, MN., Bruckmann, M. Modem solutions for industrial matrix-converter applications. IEEE Trans Ind Electron 2002; 49(2): 401-6.

[4] Farshad, Soltanian. A Review of Commutation Problem in Matrix Converter. International Journal of Computers 2019; 13: 1-10.

[5] Hsin-Liang, Chen., Chi-Hsiung, Wang., Jen-Shiun, Chiang2. Reconfigurable Double-Sampled Cascaded SigmaDelta Modulator with Power Minimizing and System Stabilizing Strategy for Multi-Mode Applications. Journal of Applied Science and Engineering 2020; 23(4): 643-654.

[6] Zeng, R., Xu, L., Yao, L., Williams, BW. Design and operation of a hybrid modular multilevel converter. IEEE Trans Power Electron 2015; 30(3): 1137-46.

[7] Xu, J., Zhao, P., Zhao, C. Reliability analysis and redundancy configuration of MMC with hybrid submodule topologies. IEEE Trans Power Electron 2016; 31(4): 2720-9.T

[8] Merlin, MM., Green, TC., Mitcheson, PD., Trainer, DR., Critchley, R., Crookes, W., et al. The alternate arm converter: a new hybrid multilevel converter with DC-fault blocking capability. IEEE Trans. Power Del. 2014; 29(1): 310-7.

[9] Merlin, MM., Green, TC. Cell capacitor sizing in multilevel converters: cases of the modular multilevel converter and alternate arm converter. IET Power Electron 2015; 8(3): 350-60.

[10] Gruson, F., Vermeersch, P., Guillaud, X., Egrot, P. Energy control for the alternate arm converter. Proc IEEE Manchester PowerTech Manchester UK 2017; $1-6$.

[11] Razani, R., Ravanji, MH., Parniani, M. Enhanced hybrid modular multilevel converter with improved reliability and performance characteristics. IEEE Trans Power Electron 2019; 34(4): 3139-49.

[12] Kang, J., Kim, H., Jung, H-J., Lee, D-S., Kim, C-K., Mantooth, HA., et al. On exploiting active redundancy of a modular multilevel converter to balance reliability and operational flexibility. IEEE Trans Power Electron 2019; 34(3): 2234-43.

[13] Tu, P., Yang, S., Wang, P. Reliability and cost based redundancy design for modular multilevel converter. IEEE Trans Ind Electron 2019; 66(3): 2333-42.

[14] Bennouk, A., Nejmi, A., Ramzi, M. A Lyapunov Based Approach to Enchance Wind Turbine Stability. Indonesian Journal of Electrical Engineering and Informatics (IJEEI) 2017; 5(2): 145-154.

[15] Bin Dai., Weizhang, Song. Research on Vector Control of Variable Speed Constant Frequency Wind Power Generation System Fed by TSMC-DFIG. Journal of Applied Science and Engineering 2017; $20(2)$ : $243-250$.

[16] Leclercq, L., Robyns, B., Grave, JM. Control based on fuzzy logic flywheel energy storage system associated with wind and diesel generators. Math Comput Simulat 2003; 63(3-5): 271-80.

[17] Pena, R., Cardenas, R., Reyes, E., Clare, J., Wheeler, P. Control of DFIG via an indirect matrix converter with changing DC voltage. IEEE Trans Ind Electron 2010; 58(10): 4664-74.

[18] Pena, R., Cardenas, R., Reyes, E., Clare, J., Wheeler, P. Control of DFIG via an indirect matrix converter with changing DC voltage. IEEE Trans Ind Electron 2010; 58(10): 4664-74.

[19] Chellaswamy, C., Muthammal, R., Pragadeeshkumar, N., Ramesh, R. Reduction of Power Fluctuation in Wind Turbine Using Variable Frequency Transformer and Optimized PID Controller. Asian Journal of Applied Sciences 2017; 5(5): 868-877.

[20] Xu, J., Zhao, P., Zhao, C. Reliability analysis and redundancy configuration of MMC with hybrid submodule topologies. IEEE Trans Power Electron 2016; 31(4): 2720-9.

[21] Xu, J., Wang, L., Wu, D., Jing, H., Zhao, C. Reliability modeling and redundancy design of hybrid MMC considering decoupled sub-module correlation. Int. J. Electr. Power Energy Syst. 2019; 105: 690-8.

[22] Wang, M., Hu, Y., Zhao, W., Wang, Y., Chen, G. Application of modular multilevel converter in medium voltage high power permanent magnet synchronous generator wind energy conversion systems. IET Renew. Power Gener. 2016; 10(6): 824-33.

[23] Kim, C., Lee, S. Redundancy determination of HVDC MMC modules. Electronics 2015; 4(3): 526-37.

[24] Diaz, Matias., Cardenas, Roberto., Espinoza, Mauricio., Hackl, Christoph M., Rojas, Felix., Clare, Jon C., Wheeler, Patrick. Vector Control of a Modular Multilevel Matrix Converter Operating in the Full Output-Frequency Range. IEEE Transactions on Industrial Electronics, 2018; 66(7): 5102-5114.

[25] Xie, X., Li, H., Hu, Y., Yang, T., Wu, Y., Chai, Z. Analysis of power loss and reliability on hybrid modular multilevel converter with redundancy configuration for offshore wind turbines. Proc Int Conf Elect Mach Syst Harbin China 2019; 1-6.

[26] Yu, X., Khambadkone, AM. Reliability analysis and cost optimization of parallel-inverter system. IEEE Trans Ind Electron 2012; 59(10): 3881-9.

[27] Chellaswamy, C., Chiranjeevi, M., Balaji, L., Saravanan, M. Fuzzy Logic Based PIDF Controller for PV Array Fed Multilevel Converter. IEEE International Conference on Algorithms, Methodology, Models and Applications in Emerging Technologies (ICAMMAET) 2017; 1-6.

[28] Diaz, M., Cardenas, R., Espinoza, M., Rojas, F., Mora, A., Clare, J. C., Wheeler, P. Control of wind energy conversion systems based on the modular multilevel matrix converter. IEEE Transactions on Industrial Electronics 2017; 64(11): $1-11$ 
[29] Kawamura, W., Hagiwara, M., Akagi, H. Control and experiment of a modular multilevel cascade converter based on triple-star bridge cells. IEEE Transactions on Industry Applications 2014; 50(5): 3536-3548.

[30] Kammerer, F., Kolb, J., Braun, M. Fully decoupled current control and energy balancing of the Modular Multilevel Matrix Converter. 15th International Power Electronics and Motion Control Conference and Exposition 2012; 3-8.

[31] Abdelhamid, S., Messaoud, H., Mounir, K. PV/Wind Hybrid Energy System, Modeling and Simulation at variable weather conditions. Indonesian Journal of Electrical Engineering and Informatics (IJEEI) 2020; 8(4): 637-647.

[32] Espinoza, M., Cardenas, R., D'1az, M., Clare, J. An Enhanced dq-based vector control system for modular multilevel converters feeding variable-speed drives. IEEE Trans. Ind. Electron. 2017; 64(4): 2620-2630.

[33] Diaz, M. Control of the Modular Multilevel Matrix Converter for Wind Energy Conversion Systems, University of Nottingham, Available: http://eprints.nottingham.ac.uk/47157/2/PhD Thesis Matias Diaz\%0A UoN October 2017.pdf.

[34] Perez, M., Bernet, S., Rodriguez, J., Kouro, S., Lizana, R. Circuit topologies, modelling, control schemes and applications of modular multilevel converters. IEEE Transactions on Power Electronics 2014; 30(1): 1-17.

[35] Pena, Ruben., Cardenas, Roberto., Asher, Greg. Overview of control systems for the operation of DFIGs in wind energy applications, IECON Proc. (Industrial Electron. Conf. 2013; 60(7): 88-95.

[36] Casanellas, F. Losses in PWM inverters using IGBTs. Proc Inst Elect Eng-Electr Power Appl 1994; 141(5): $235-9$.

[37] Lu, S., Yuan, L., Li, K., Zhao, Z. An improved phase-shifted carrier modulation scheme for a hybrid modular multilevel converter. IEEE Trans Power Electron 2017; 32(1): 81-97.

[38] Li, B., Yang, R., Xu, D., Wang, G., Wang, W., Xu, D. Analysis of the phase-shifted carrier modulation for modular multilevel converters. IEEE Trans Power Electron 2015; 30(1): 297-310. 